\title{
Cardiac catheterization within 24 hours of valve surgery is significantly associated with acute renal failure
}

\author{
Sara A. Hennessy, MD, Damien J. LaPar, MD, George J. Stukenborg, PhD, Matthew L. Stone, MD, \\ Ryan A. Mlynarek, BS, John A. Kern, MD, Gorav Ailawadi, MD, and Irving L. Kron, MD
}

\begin{abstract}
Objective: Acute renal failure after valve surgery carries significant morbidity and mortality. Preoperative cardiac catheterization is the standard of care. For convenience, catheterization just before surgery is simplest for patients. However, it is not known if this timing of radiocontrast administration significantly affects renal function. We hypothesized that preoperative cardiac catheterization within 24 hours of valve surgery is associated with the development of acute renal failure.
\end{abstract}

Methods: A retrospective case-control study was performed of all patients undergoing valve surgery between 2003 and 2008 at the University of Virginia. Patients with preoperative renal dysfunction were excluded. Patients with postoperative acute renal failure were matched to those without acute renal failure according to age, gender, year of surgery, New York Heart Association functional class, elective status, concomitant coronary artery bypass grafting, and type of valve procedure. A logistic regression model examined the effects of perioperative risk factors on the development of acute renal failure.

Results: Of 1287 patients undergoing valve surgery, 61 with acute renal failure were matched to 136 without acute renal failure. Cardiac catheterization within 24 hours of surgery was significantly greater in patients with acute renal failure $(31.2 \%$ vs $8.8 \%, P=.013)$. The risk of acute renal failure was more than 5 times higher for patients undergoing catheterization within 24 hours of surgery (odds ratio, $5.3 ; P=.004$ ). The number of postoperative vasopressors was significantly associated with acute renal failure (odds ratio, $1.7 ; P=.007$ ).

Conclusions: Although catheterization is often performed for patient convenience, catheterization within 24 hours of valve surgery is significantly associated with the development of acute renal failure. Current practices should be adjusted to ensure that more than 24 hours have passed from the time of cardiac catheterization to valve surgery in elective settings. (J Thorac Cardiovasc Surg 2010;140:1011-7)

Acute renal failure (ARF) is a serious and unfortunately common complication after cardiac surgery occurring in up to $30 \%$ of patients. ${ }^{1-6}$ Furthermore, valvular heart surgery is an independent risk factor for ARF, conferring a 2.7-fold increased risk compared with coronary artery bypass grafting (CABG) alone. ${ }^{7}$ Contrast-induced nephropathy accounts for a significant number of cases of hospital-acquired $\mathrm{ARF},{ }^{8-10}$ and ARF is associated with a $20 \%$ mortality rate after cardiac catheterization. ${ }^{11,12}$ Previous studies have suggested a temporal relationship between the timing of cardiac

\footnotetext{
From the Department of Surgery, University of Virginia, Charlottesville, Va. The project described was supported by Award Number T32HL007849 from the National Heart, Lung, and Blood Institute. The content is solely the responsibility of the authors and does not necessarily represent the official views of the National Heart, Lung, and Blood Institute or the National Institutes of Health.

Disclosures: Gorav Ailawadi: Consultant for Atricure, Carbomedic, St Jude, and Honoraria: Atricure, Abbott. Irving L. Kron: Consultant for Edwards Life Sciences, St Jude.

Read at the 90th Annual Meeting of The American Association for Thoracic Surgery, May 1-5, 2010, Toronto, Ontario, Canada.

Received for publication April 29, 2010; revisions received June 12, 2010; accepted for publication Aug 20, 2010; available ahead of print Sept 10, 2010.

Address for reprints: Irving L. Kron, MD, University of Virginia Health System, PO Box 800679, Charlottesville, VA 22908 (E-mail: ilk@virginia.edu). 0022-5223/\$0.00

Published by Elsevier Inc. on behalf of The American Association for Thoracic Surgery

doi:10.1016/j.jtcvs.2010.07.056
}

catheterization and the development of $\mathrm{ARF}$ in patients undergoing $\mathrm{CABG}$ and combination cardiac procedures. ${ }^{13-15}$

It is unclear whether timing of radiocontrast administration for cardiac catheterization significantly affects renal function after heart valve surgery. Elective cardiac catheterization is often performed the day before surgery for convenience. We hypothesized that preoperative cardiac catheterization within 24 hours of heart valve surgery is associated with the development of ARF.

\section{MATERIALS AND METHODS}

Data Source and Patient Population

Approval for this investigation was obtained from the human investigation committee of the University of Virginia Health System, including a waiver of the need to obtain patient consent. All patients undergoing cardiac surgery at the University of Virginia were prospectively entered into the Society of Thoracic Surgeons (STS) database.

A retrospective review was performed of all patients who underwent heart valve surgery (repair or replacement) from August 2003 to December of 2008 . The 1287 patients identified were stratified as those with postoperative ARF (ARF group) and without postoperative ARF (no ARF group) All patients with preoperative renal failure or renal dysfunction were excluded from the study.

\section{Variables Examined and Outcomes Measured}

Renal failure or dysfunction was defined on the basis of accepted STS definitions. ${ }^{16}$ Postoperative ARF was defined as any patient with an increase 


$$
\begin{aligned}
& \text { Abbreviations and Acronyms } \\
& \begin{aligned}
\text { ARF } & =\text { acute renal failure } \\
\text { CABG } & =\text { coronary artery bypass grafting } \\
\text { CI } & =\text { confidence interval } \\
\text { CPB } & =\text { cardiopulmonary bypass } \\
\text { OR } & =\text { odds ratio } \\
\text { STS } & =\text { Society of Thoracic Surgeons }
\end{aligned}
\end{aligned}
$$

of serum creatinine to greater than $2.0 \mathrm{mg} / \mathrm{dL}$ and 2 times the most recent preoperative creatinine level or the requirement for dialysis postoperatively. Preoperative renal failure or dysfunction was defined as a documented history of renal failure, a history of a creatinine level greater than $2.0 \mathrm{mg} / \mathrm{dL}$, or the need for current dialysis.

Patient demographic characteristics, preoperative risk factors, operative features, and postoperative outcomes were examined. STS definitions were used to describe all preoperative variables, postoperative complications, and outcomes. ${ }^{16}$ In this population, epinephrine was commonly used during low cardiac output and norepinephrine/vasopressin/phenylephrine was used for a vasoplegic state. Mortality was defined as any patient death that occurred before hospital discharge or within 30 days of operation. A major complication included the composite incidence of postoperative stroke, mortality, infection, and prolonged ventilation. Timing of cardiac catheterization to surgery was defined as less than 24 hours, 24 to 48 hours, 48 to 72 hours, and greater than 72 hours. The following postoperative vasopressor administration was recorded for each patient during the first 6 hours after surgery: epinephrine, norepinephrine, vasopressin, and phenylephrine. Each patient's preoperative hemoglobin (grams/deciliter) and lowest intraoperative hemoglobin (grams/deciliters) were collected and subsequently used to calculate change in intraoperative hemoglobin (grams/deciliters). In addition, the highest rewarming temperature (degrees Celsius) was recorded for each patient after cardiopulmonary bypass (CPB).

The primary end point was the development of ARF after heart valve surgery. The influence of perioperative variables on the development of ARF was studied.

\section{Statistical Analysis}

A case-control study was performed on the 1287 patients who underwent heart valve surgery. Patients with ARF were matched to patients without ARF according to age, gender, year of surgery, New York Heart Association functional class, elective versus emergent/urgent operative status, concomitant $\mathrm{CABG}$, and type of valve procedure (aortic, mitral, tricuspid, and pulmonic valves). Year of surgery was matched to within 1 year, and age of the patient at the time of surgery was matched to within 5 years. Case-control matching was performed using Bergstralh and colleagues' algorithm. ${ }^{17} \mathrm{Up}$ to 3 controls were matched to each case in the study population to maximize the balance achieved across criteria in the available population. ${ }^{18}$ The adequacy of the balance achieved between cases and controls was formally assessed using the chi-square test statistic for all categoric matching criteria and the $t$ test statistic to assess the significance of the difference in mean age.

Patient demographic, preoperative risk factors, operative features, and postoperative outcomes were compared using a univariate analysis. Categoric variables were compared using the chi-square or Fisher's exact test where appropriate. Continuous variables were compared using a 2-sided $t$ test.

A multivariable conditional logistic regression was performed to assess the statistical significance of the association between ARF and a series of exposures of interest. ${ }^{19}$ The following variables were entered as covariates: preoperative angiotensin-converting enzyme inhibitor or angiotensin II receptor blocker use, timing of cardiac catheterization before surgery (within 24 hours, $24-48$ hours, $48-72$ hours, or $\geq 72$ hours), intraoperative aprotinin use, number of postoperative vasopressors, lowest intraoperative hemoglobin, change in hemoglobin, and highest CPB rewarming temperature and $\mathrm{CPB}$ time. These covariates were chosen a priori on the basis of the literature and clinical knowledge. CPB time was significantly different between the $\mathrm{ARF}$ and no ARF groups and therefore included in the logistic regression to account for that difference. Other established risk factors for ARF (age, diabetes, degree of heart failure, urgent/emergent operative status) were controlled for in the case-control analysis. Patients in the ARF group and the no ARF group were equal according to these established risk factors and therefore not included in the multivariable analysis.

Conditional logistic regression was performed using the discrete logistic form of the Cox proportional hazards model with strata formed for each matched set. Cases and controls were compared and assessed for significant differences on each exposure of interest using the Wald chi-square test statistic. The magnitude of differences in renal failure complications for each exposure was measured by calculating odds ratios (ORs), and $95 \%$ confidence intervals $(\mathrm{CI})$ were calculated to assess the statistical significance of the difference in odds between cases and controls. Data manipulation and analysis were performed with SAS version 9.1.3 software (SAS Institute, Inc, Cary, NC)

\section{RESULTS}

From August 2003 to December 2008, 1287 patients underwent heart valve surgery at the University of Virginia. Of this cohort, 83 patients $(6.6 \%)$ had postoperative ARF and $52 \%$ of these patients required dialysis. Records for patients without ARF were searched to find patients of identical age, gender, New York Heart Association functional class, elective status or emergent/urgent operative status, concomitant CABG, year of surgery, and type of valve procedure. A total of 61 patients with ARF were matched to 136 patients without ARF, with 61 cases matched to at least 1 control, 44 cases matched twice, and 31 cases matched to 3 controls. Of the 83 patients with ARF, 22 were excluded from the study because there was no suitable match to a patient without ARF according to our matching criteria.

\section{Preoperative Risk Factors and Operative Features}

As seen in Table 1, balance was achieved across all matching criteria, such that no statistically significant differences were observed in the proportional distributions or mean values of the matching covariates. The number of patients in the ARF group was equal to the number of patients in the no ARF group according to elective versus emergent/ urgent operative status (emergent/urgent status: $41 \%$ vs $37.5 \%, P=.76)$.

Preoperative creatinine was not significantly different between the ARF and no ARF groups $(1.21 \pm 0.04 \mathrm{mg} / \mathrm{dL}$ vs $1.12 \pm 0.02 \mathrm{mg} / \mathrm{dL}, P=.06$ ). Preoperative risk factors in patients with ARF were equivalent to patients without ARF (Table 2). There was no statistically significant difference in STS-predicted risk between patients with and without ARF $(8 \% \pm 8 \%$ vs $6 \% \pm 6 \%, P=.31)$. There was no difference in diabetes ( $24 \%$ vs $30.2 \%, P=.42)$, hypertension $(73.8 \%$ vs $72.1 \%, P=.80)$, or dyslipidemia $(68.9 \%$ vs $66.9 \%, P=.79)$. Patients with ARF differed from patients without ARF on several perioperative factors (Table 3). Patients with ARF 
TABLE 1. Summary of matching criteria for patients with and without acute renal failure

\begin{tabular}{|c|c|c|c|}
\hline & $\begin{array}{c}\text { ARF } \\
(\mathbf{n}=\mathbf{6 1})(\%)\end{array}$ & $\begin{array}{c}\text { No ARF } \\
(\mathbf{n}=\mathbf{1 3 6})(\%)\end{array}$ & $\begin{array}{c}P \\
\text { value* }\end{array}$ \\
\hline $\begin{array}{l}\text { Age at operation } \\
\qquad(\mathrm{y}, \text { mean } \pm \mathrm{SD})\end{array}$ & $67 \pm 13.9$ & $67.7 \pm 13.7$ & .77 \\
\hline Male & $29(47.5 \%)$ & $68(50.0 \%)$ & .75 \\
\hline Year of surgery & & & .61 \\
\hline 2003 & $2(3.3 \%)$ & $3(2.2 \%)$ & \\
\hline 2004 & $5(8.2 \%)$ & $17(12.5 \%)$ & \\
\hline 2005 & $10(16.4 \%)$ & $13(9.6 \%)$ & \\
\hline 2006 & $6(9.8 \%)$ & $21(15.4 \%)$ & \\
\hline 2007 & $18(29.5 \%)$ & $38(27.9 \%)$ & \\
\hline 2008 & $20(32.8 \%)$ & $44(32.4 \%)$ & \\
\hline NYHA functional class & & & .92 \\
\hline 1 & $23(37.7 \%)$ & $55(40.4 \%)$ & \\
\hline 2 & $7(11.5 \%)$ & $18(13.2 \%)$ & \\
\hline 3 & $12(19.7 \%)$ & $22(16.2 \%)$ & \\
\hline 4 & $19(31.2 \%)$ & $41(30.2 \%)$ & \\
\hline Operative status & & & .76 \\
\hline Elective surgery & $36(59.0 \%)$ & $85(62.5 \%)$ & \\
\hline Emergent/urgent surgery & $25(41.0 \%)$ & $51(37.5 \%)$ & \\
\hline CABG & $25(41.0 \%)$ & $58(42.7 \%)$ & .83 \\
\hline \multicolumn{4}{|l|}{$\begin{array}{l}\text { Type of valve surgery } \\
\text { (repair or replacement) }\end{array}$} \\
\hline Aortic & $42(68.9 \%)$ & $100(73.5 \%)$ & .50 \\
\hline Mitral & $20(32.8 \%)$ & $37(27.2 \%)$ & .42 \\
\hline Pulmonic & $1(1.6 \%)$ & $1(0.74 \%)$ & .56 \\
\hline Tricuspid & $3(4.9 \%)$ & $5(3.7 \%)$ & .68 \\
\hline
\end{tabular}

$\overline{A R F}$, Acute renal failure; $N Y H A$, New York Heart Association; $C A B G$, coronary artery bypass grafting. *Significance $<.05$.

were more likely to have their cardiac catheterization less than 24 hours from the time of surgery $(31.2 \%$ vs $8.8 \%$, $P<.0001)$. CPB time was longer in the ARF group $(156.2 \pm 73.4$ minutes vs $133.7 \pm 46.4$ minutes, $P=.03)$. In the first 6 postoperative hours, patients with ARF were more likely to receive norepinephrine $(61.7 \%$ vs $38.7 \%$, $P=.002)$ and vasopressin $(60 \%$ vs $37.3 \%, P=.003)$.

\section{Association Between Acute Renal Failure and Postoperative Outcomes}

After valve surgery, patients with ARF had significantly worse postoperative complications compared with patients without ARF. Patients with ARF were more likely to undergo reoperation secondary to postoperative bleeding or tamponade $(16.4 \%$ vs $5.9 \%, P=.02)$. These patients were also more likely to have postoperative sepsis, pneumonia, a gastrointestinal complication, and noncardiac reoperation (Table 4). ARF was associated with prolonged ventilation $(68.3 \%$ vs $16.2 \%, P<.0001)$, longer intensive care unit stays ( $384.7 \pm 444.3$ hours vs $79.2 \pm 72.7$ hours, $P<.0001$ ), and longer length of stays in the hospital $(24.3 \pm 21.3$ days vs $8 \pm 4.8$ days, $P<.0001)$.

Overall major complication rates were significantly higher in patients with acute ARF $(20 \%$ vs $5.1 \%$,
TABLE 2. Preoperative risk factors for patients with and without acute renal failure after valve surgery

\begin{tabular}{lccc}
\hline & $\begin{array}{c}\text { ARF } \\
(\mathbf{n}=\mathbf{6 1})(\%)\end{array}$ & $\begin{array}{c}\text { No ARF } \\
(\mathbf{n}=\mathbf{1 3 6})(\%)\end{array}$ & $\begin{array}{c}\boldsymbol{P} \\
\text { value* }\end{array}$ \\
\hline Ethnicity & & & .73 \\
$\quad$ Caucasian & $58(96.7 \%)$ & $123(94.0 \%)$ & \\
$\quad$ African-American & $2(3.3 \%)$ & $8(6.1 \%)$ & \\
History of tobacco & $25(41.0 \%)$ & $57(41.9 \%)$ & .90 \\
Dyslipidemia & $42(68.9 \%)$ & $91(66.9 \%)$ & .79 \\
Peripheral artery disease & $10(16.7 \%)$ & $16(11.8 \%)$ & .37 \\
Cerebrovascular disease & $12(20.0 \%)$ & $29(21.2 \%)$ & .79 \\
Chronic lung disease & $10(16.4 \%)$ & $27(19.9 \%)$ & .57 \\
Previous CVA & $9(14.8 \%)$ & $17(12.5 \%)$ & .67 \\
Diabetes & $15(24.0 \%)$ & $41(30.2 \%)$ & .42 \\
Hypertension & $45(73.8 \%)$ & $98(72.1 \%)$ & .80 \\
Preoperative creatinine & $1.21 \pm 0.02$ & $1.12 \pm 0.04$ & .06 \\
$\quad$ (m)/dL, mean \pm SD) & & & \\
ACE inhibitor/ARB use & $23(37.7 \%)$ & $55(40.4 \%)$ & .72 \\
Immunosuppressive & $5(8.2 \%)$ & $10(7.4 \%)$ & .78 \\
$\quad$ Medication & & & \\
Previous CABG & $5(8.2 \%)$ & $11(8.1 \%)$ & 1 \\
Previous valve procedure & $6(9.8 \%)$ & $15(11.0 \%)$ & .80 \\
Arrhythmia & $15(25.6 \%)$ & $37(27.2 \%)$ & .70 \\
Angina & $14(23.0 \%)$ & $39(28.7 \%)$ & .40 \\
Heart failure & $33(54.1 \%)$ & $59(43.4 \%)$ & .16 \\
\hline ARF Ace & &
\end{tabular}

$\overline{A R F}$, Acute renal failure; $C V A$, cerebrovascular accident; $A C E$, angiotensinconverting enzyme inhibitor; $A R B$, angiotensin II receptor blocker; $S D$, standard deviation; $C A B G$, coronary artery bypass grafting. *Significance $<.05$.

$P=.003)$. The 30-day mortality was significantly higher in patients with $\operatorname{ARF}(18.3 \%$ vs $5.1 \%, P=.004)$.

\section{Risk Factors for Acute Renal Failure}

The logistic regression identifies 2 risk factors associated with the development of postoperative ARF (Table 5). The risk of ARF was more than 5 times higher for patients who underwent cardiac catheterization within 24 hours of their valve surgery compared with patients who underwent cardiac catheterization more than 72 hours before valve surgery (OR, 5.3; CI, 1.9-15.2; $P=.004)$. The administration of vasopressors in the first 6 postoperative hours was also significantly associated with the development of ARF. The risk of $\mathrm{ARF}$ increased 2-fold for every additional vasopressor given (OR, 1.7; CI, 1.2-2.4; $P=.007)$.

\section{DISCUSSION}

$\mathrm{ARF}$ is a potentially devastating complication after heart valve surgery. It is often associated with a complicated clinical course and holds significant morbidity for patients, with increased resource use, longer hospital stays, and increased risk of infection. Patients requiring dialysis have exceptionally high mortality rates ranging from $20 \%$ to $64 \%, 3,20,21$ and even small increases in serum creatinine are associated with an increase in 30-day mortality. ${ }^{22}$

In this study, ARF developed in $6.6 \%$ of patients undergoing valve surgery with no history of renal dysfunction, 
TABLE 3. Perioperative features for patients undergoing valve surgery

\begin{tabular}{|c|c|c|c|}
\hline & $\begin{array}{c}\text { ARF } \\
(n=61)(\%)\end{array}$ & $\begin{array}{c}\text { No ARF } \\
(n=136)(\%)\end{array}$ & $\begin{array}{c}P \\
\text { value* }\end{array}$ \\
\hline $\begin{array}{l}\text { STS predicted risk } \\
\quad(\text { mean } \pm \mathrm{SD})\end{array}$ & $8 \pm 8.0 \%$ & $6 \pm 6.0 \%$ & .31 \\
\hline IABP & $8(13.1 \%)$ & $11(8.1 \%)$ & .27 \\
\hline $\begin{array}{l}\text { Cardiac catheterization } \\
\text { within } 24 \mathrm{~h}\end{array}$ & $19(31.2 \%)$ & $12(8.8 \%)$ & $<.0001^{*}$ \\
\hline $\begin{array}{l}\text { Cardiac catheterization } \\
\text { within } 24-48 \mathrm{~h}\end{array}$ & $2(3.3 \%)$ & $25(18.4 \%)$ & $.003^{*}$ \\
\hline $\begin{array}{l}\text { Cardiac catheterization } \\
\text { within } 48-72 \mathrm{~h}\end{array}$ & $7(11.5 \%)$ & $8(5.9 \%)$ & .24 \\
\hline $\begin{array}{l}\text { Cardiac catheterization } \\
>72 \mathrm{~h} \text { before }\end{array}$ & $33(54.1 \%)$ & $90(66.2 \%)$ & .11 \\
\hline $\mathrm{CPB}$ time (min, mean $\pm \mathrm{SD}$ ) & $156.2 \pm 73.4$ & $133.7 \pm 46.4$ & $.03 *$ \\
\hline Aprotinin & $17(27.9 \%)$ & $24(17.7 \%)$ & .10 \\
\hline Epinephrine & $50(80.0 \%)$ & $102(74.3 \%)$ & .24 \\
\hline Norepinephrine & $37(60.7 \%)$ & $53(39.0 \%)$ & $.005^{*}$ \\
\hline Vasopressin & $37(60.7 \%)$ & $50(36.8 \%)$ & $.002 *$ \\
\hline Phenylephrine & $4(6.6 \%)$ & $6(4.4 \%)$ & .50 \\
\hline $\begin{array}{l}\text { Intraoperative change in } \\
\quad \text { hemoglobin (mean } \pm \mathrm{SD})\end{array}$ & $5.5 \pm 1.9$ & $5.41 \pm 1.9$ & .76 \\
\hline $\begin{array}{l}\text { Lowest intraoperative } \\
\quad \text { hemoglobin }(\text { mean } \pm \mathrm{SD})\end{array}$ & $7 \pm 1.5$ & $7.2 \pm 1.2$ & .21 \\
\hline $\begin{array}{l}\text { Highest post-CPB re-warming } \\
\text { temperature }\end{array}$ & $36.9 \pm 0.86$ & $36.6 \pm 0.64$ & $.04 *$ \\
\hline
\end{tabular}

and more than $50 \%$ of these patients progressed to dialysis. Of these patients, $6 \%$ had a major postoperative complication with an $18 \%$ 30-day mortality rate. Similar to patients described in the literature, ${ }^{1-3,6,23-25}$ patients with ARF in this study had significantly worse postoperative outcomes. Patients with ARF also had longer CPB times, and therefore $\mathrm{CPB}$ time was included in the multivariable logistic regression to eliminate it as a confounder. They had higher rates of infection, longer intensive care unit

TABLE 4. Postoperative outcomes after valve surgery

\begin{tabular}{lccc}
\hline & $\begin{array}{c}\text { ARF } \\
(\mathbf{n}=\mathbf{6 1})(\%)\end{array}$ & $\begin{array}{c}\text { No ARF } \\
(\mathbf{n}=\mathbf{1 3 6})(\%)\end{array}$ & $\begin{array}{c}\boldsymbol{P} \\
\text { value* }\end{array}$ \\
\hline Sepsis & $11(18.0 \%)$ & $4(2.9 \%)$ & $<.0001^{*}$ \\
Deep sternal wound infection & $1(1.6 \%)$ & $0(0)$ & .31 \\
Stroke & $7(11.5 \%)$ & $10(7.4 \%)$ & .34 \\
Reoperation for bleeding or & $10(16.4 \%)$ & $8(5.9 \%)$ & $.02^{*}$ \\
$\quad$ & & & \\
$\quad$ tamponade & $14(23.0 \%)$ & $5(3.7 \%)$ & $<.0001^{*}$ \\
Goncardiac reoperation & $13(21.7 \%)$ & $2(1.5 \%)$ & $<.001^{*}$ \\
Pneumonia & $18(29.5 \%)$ & $6(4.4 \%)$ & $<.001^{*}$ \\
Prolonged ventilation & $42(68.3 \%)$ & $22(16.2 \%)$ & $<.000^{*}$ \\
Length of stay (d, mean $\pm \mathrm{SD})$ & $24.3 \pm 21.3$ & $8 \pm 4.8$ & $<.0001^{*}$ \\
ICU stay (h, mean $\pm \mathrm{SD})$ & $384.7 \pm 444.3$ & $79.2 \pm 72.7$ & $<.0001^{*}$ \\
Mortality (30 d) & $11(18.3 \%)$ & $7(5.1 \%)$ & $.004^{*}$ \\
\hline
\end{tabular}

$I C U$, Intensive care unit; $S D$, standard deviation. *Significance $<.05$.
TABLE 5. Conditional logistic regression model: Predictors of acute renal failure

\begin{tabular}{|c|c|c|c|}
\hline & $\begin{array}{l}\text { Odds } \\
\text { ratio }\end{array}$ & $\begin{array}{l}95 \% \text { Confidence } \\
\text { interval }\end{array}$ & $\begin{array}{c}P \\
\text { value* }\end{array}$ \\
\hline $\begin{array}{l}\text { Cardiac catheterization } \\
\text { within } 24 \mathrm{~h}\end{array}$ & 5.3 & $1.4-19.0$ & $.01 *$ \\
\hline $\begin{array}{l}\text { Cardiac catheterization } \\
\text { within } 24-48 \mathrm{~h}\end{array}$ & 0.4 & $0.1-2.8$ & .47 \\
\hline $\begin{array}{l}\text { Cardiac catheterization } \\
\text { within } 48-72 \mathrm{~h}\end{array}$ & 3.1 & $0.8-12.3$ & .11 \\
\hline $\begin{array}{l}\text { Cardiac catheterization } \\
\quad>72 \mathrm{~h} \text { before }\end{array}$ & REF & REF & REF \\
\hline $\begin{array}{l}\text { No. of postoperative vasopressors } \\
\text { (in first } 6 \mathrm{~h} \text { ) }\end{array}$ & 1.7 & $1.2-2.4$ & $.007 *$ \\
\hline Preoperative ACE inhibitors/ARB & 1.0 & $0.5-2.1$ & .37 \\
\hline Aprotinin & 1.3 & $0.3-2$ & .61 \\
\hline Change in hemoglobin & 1.0 & $0.8-1.2$ & .96 \\
\hline Lowest intraoperative hemoglobin & 0.8 & $0.6-1.1$ & .23 \\
\hline $\begin{array}{l}\text { Highest post-CPB rewarming } \\
\text { temperature }\left({ }^{\circ} \mathrm{C}\right)\end{array}$ & 1.4 & $0.9-2.3$ & .18 \\
\hline CPB time & 1 & $1.0-1.1$ & .56 \\
\hline
\end{tabular}

stays, and overall longer hospitalizations (Table 4). Given the significant postoperative complications associated with ARF after valve surgery, identifying methods of prevention of renal injury is imperative.

Preoperative cardiac catheterization is the standard of care before valve surgery, and many patients commonly undergo both catheterization and valve surgery sequentially in a single hospitalization for convenience. The American College of Cardiology and American Heart Association Guidelines recommend preoperative cardiac catheterization before valve surgery in any man or postmenopausal woman aged 35 years or more and in any premenopausal woman with risk factors. They also recommend catheterization in mild to moderate valve disease if there is evidence of angina, ischemia, decreased left ventricular function, or overt congestive heart failure. ${ }^{26}$ Currently, the temporal relationship between cardiac catheterization and surgery on the development of ARF has primary focused on CABG and combination cardiac procedures. We lack specific insight on the nature of this relationship for patients undergoing valve repair and replacement procedures.

In patients undergoing CABG, Medalion and colleagues, ${ }^{14}$ as well as others, ${ }^{13}$ reported surgery within 5 days of cardiac catheterization was as an independent predictor of postoperative ARF. Ranucci and colleagues ${ }^{15}$ found that delaying cardiac surgery more than 24 hours from the time of cardiac catheterization decreased the incidence of postoperative ARF by 3-fold. On the other hand, Brown and colleagues ${ }^{27}$ suggest in a select population that sameday coronary angiography may be safe before valve surgery. 
Our study focuses on this temporal relationship in patients undergoing valve surgery and collaborates the findings after CABG and combined cardiac procedures. The timing of cardiac catheterization was a significant predictor of ARF. Catheterization within 24 hours of surgery was significantly greater in patients with ARF than in patients without ARF $(31.2 \%$ vs $8.8 \%, P=.01)$. The risk of ARF was more than 5 times higher for patients who underwent cardiac catheterization within 24 hours of surgery compared with patients who underwent catheterization more than 72 hours before surgery (OR, 5.3; CI, 1.9-15.2; $P=.004$ ).

Contrast-induced nephropathy after cardiac catheterization and ARF after valve surgery have been well described in the literature. Contrast administration and valve surgery likely have synergistic effects on the kidney, causing renal dysfunction. Contrast administration likely decreases the functional reserve of the kidneys ("first hit"), making patients less likely to withstand a "second hit," which is either the valve procedure itself or any postoperative complication such as bleeding or a need for vasopressors. Increasing the time between cardiac catheterization and valve surgery may limit this multiple hit phenomenon. When feasible, performing cardiac catheterization more than 24 hours before the time of valve surgery is recommended.

Notably, the administration of postoperative vasopressors was significantly associated with the development of ARF after valve surgery. The use of these agents has been associated with the development of postoperative renal failure after cardiac surgery. ${ }^{28-31}$ However, previous studies have failed to identify postoperative vasopressor use as a significant independent predictor of ARF. ${ }^{28,30}$ In our study, patients with ARF were more likely to receive norepinephrine and vasopressin than patients without ARF. Furthermore, postoperative vasopressor use was found to be predictive of ARF, with a 2-fold increased risk for every additional vasopressor given (OR, 1.7; CI, 1.2-2.4; $P=.007$ ).

Cardiac performance has been described as one of the critical factors in the development of ARF after cardiac surgery. ${ }^{31}$ The conflicting results between our study and others may be explained by patient selection. Currently it is ambiguous whether vasopressor use is the cause of ARF or a marker of severity of illness in these patients. Unlike other studies, our study controlled for the degree of heart failure and overall severity of preoperative illness, and the patients in the ARF and no ARF groups were identical. Therefore, in our study we concluded that vasopressor administration is predictive of ARF independently of heart failure and overall severity of illness in the patient.

\section{Limitations}

This is a small retrospective, case-control study, and therefore it is limited by its inherent biases and inability to indicate absolute risk. We recognize there are other potential modifiable risk factors for ARF that were not addressed in our analysis. One potential confounder in this study is the significant difference in postoperative complications between patients with and without ARF. Patients with ARF had higher rates of postoperative complications. This may be the cause of ARF in some patients; however, on the basis of these data, it is difficult to tease out which came first: ARF or the other postoperative complications.

ARF was defined on the basis of STS database criteria; however, they are several other definitions of renal failure (Risk Injury Failure Loss ESKD/RIFLE/Acute Kidney Injury Network) that could be used to describe this population. However, STS definitions are widely accepted and followed in our field. The difference of 1.1 and 1.2 was not significant, although it was close. In a young patient, that difference might not be of importance, whereas in an older patient a difference of 0.1 might be significant. However, in this study our patients were well matched on age and other comorbidities; therefore, this difference is likely not significant overall. However, STS definitions are well established and the definition of ARF is a conservative one; therefore, we think our conclusions are accurate and appropriate. We also recognize that it is not always feasible to delay the time from cardiac catheterization to valve surgery in all patients; however, a concerted effort should be made.

\section{CONCLUSIONS}

ARF is a significant complication after heart valve surgery. Cardiac catheterization is often performed less than 24 hours before valve surgery for convenience. However, we demonstrate that catheterization within 24 hours of valve surgery is independently associated with the development of ARF. When feasible, current practice should be adjusted to ensure that more than 24 hours have passed from the time of cardiac catheterization to the time of valve surgery.

\section{References}

1. Abel RM, Buckley MJ, Austen WG, Barnett GO, Beck CH Jr, Fischer JE Etiology, incidence, and prognosis of renal failure following cardiac operations. Results of a prospective analysis of 500 consecutive patients. J Thorac Cardiovasc Surg. 1976;71:323-33.

2. Chertow GM, Levy EM, Hammermeister KE, Grover F, Daley J. Independent association between acute renal failure and mortality following cardiac surgery. Am J Med. 1998;104:343-8.

3. Conlon PJ, Stafford-Smith M, White WD, Newman MF, King S, Winn MP, et al Acute renal failure following cardiac surgery. Nephrol Dial Transplant. 1999;14 1158-62.

4. Gailiunas P Jr, Chawla R, Lazarus JM, Cohn L, Sanders J, Merrill JP. Acute rena failure following cardiac operations. J Thorac Cardiovasc Surg. 1980;79:241-3.

5. Mangos GJ, Brown MA, Chan WY, Horton D, Trew P, Whitworth JA. Acute renal failure following cardiac surgery: incidence, outcomes and risk factors. Aust N Z J Med. 1995;25:284-9.

6. Zanardo G, Michielon P, Paccagnella A, Rosi P, Calo M, Salandin V, et al. Acute renal failure in the patient undergoing cardiac operation. Prevalence, mortality rate, and main risk factors. J Thorac Cardiovasc Surg. 1994;107:1489-95.

7. Grayson AD, Khater M, Jackson M, Fox MA. Valvular heart operation is an independent risk factor for acute renal failure. Ann Thorac Surg. 2003;75:1829-35.

8. Gleeson TG, Bulugahapitiya S. Contrast-induced nephropathy. AJR Am J Roentgenol. 2004;183:1673-89. 
9. McCullough PA, Soman SS. Contrast-induced nephropathy. Crit Care Clin 2005;21:261-80.

10. Nash K, Hafeez A, Hou S. Hospital-acquired renal insufficiency. Am J Kidney Dis. 2002;39:930-6.

11. Best PJ, Lennon R, Ting HH, Bell MR, Rihal CS, Holmes DR, et al. The impact of renal insufficiency on clinical outcomes in patients undergoing percutaneous coronary interventions. J Am Coll Cardiol. 2002;39:1113-9.

12. Rihal CS, Textor SC, Grill DE, Berger PB, Ting HH, Best PJ, et al. Incidence and prognostic importance of acute renal failure after percutaneous coronary intervention. Circulation. 2002;105:2259-64.

13. Del Duca D, Iqbal S, Rahme E, Goldberg P, de Varennes B. Renal failure after cardiac surgery: timing of cardiac catheterization and other perioperative risk factors. Ann Thorac Sur. 2007;84:1264-71.

14. Medalion B, Cohen H, Assali A, Assa HV, Farkash A, Snir E, et al. The effect of cardiac angiography timing, contrast media dose, and preoperative renal function on acute renal failure after coronary artery bypass grafting. J Thorac Cardiovasc Surg. 2010;139:1539-44.

15. Ranucci M, Ballotta A, Kunkl A, De Benedetti D, Kandil H, Conti D, et al. Influence of the timing of cardiac catheterization and the amount of contrast media on acute renal failure after cardiac surgery. J Am Coll Cardiol. 2008;101:1112-8.

16. The Society of Thoracic Surgeons - Data Collection Version 2.61. Available at, http://www.sts.org/sections/stsnationaldatabase/datamanagers/adultcardiacdb/ datacollection/index.html. Accessed March 17, 2009.

17. Bergstralh EJ, Kosanke JL, Jacobsen SJ. Software for optimal matching in observational studies. Epidemiology. 1996;7:331-2.

18. Ming K, Rosenbaum PR. Substantial gains in bias reduction from matching with a variable number of controls. Biometrics. 2000;56:118-24.

19. Hosmer DW, Lemeshow S. Applied Logistic Regression. 2nd ed. New York: John Wiley and Sons; 2000.

20. Chertow GM, Lazarus JM, Christiansen CL, Cook EF, Hammermeister KE, Grover F, et al. Preoperative renal risk stratification. Circulation. 1997;95:878-84.

21. Suen WS, Mok CK, Chiu SW, Cheung KL, Lee WT, Cheung D, et al. Risk factors for development of acute renal failure (ARF) requiring dialysis in patients undergoing cardiac surgery. Angiology. 1998;49:789-800.

22. Lassnigg A, Schmidlin D, Mouhieddine M, Bachmann LM, Druml W, Bauer P, et al. Minimal changes of serum creatinine predict prognosis in patients after cardiothoracic surgery: a prospective cohort study. J Am Soc Nephrol. 2004;15: 1597-605.

23. Anderson RJ, O'Brien M, MaWhinney S, VillaNueva CB, Moritz TE, Sethi GK, et al. Mild renal failure is associated with adverse outcome after cardiac valve surgery. Am J Kidney Dis. 2000;35:1127-34.

24. Hobson CE, Yavas S, Segal MS, Schold JD, Tribble CG, Layon AJ, et al. Acute kidney injury is associated with increased long-term mortality after cardiothoracic surgery. Circulation. 2009;119:2444-53.

25. Mehta RH, Grab JD, O'Brien SM, Bridges CR, Gammie JS, Haan CK, et al. Bedside tool for predicting the risk of postoperative dialysis in patients undergoing cardiac surgery. Circulation. 2006;114:2208-16.

26. Bonow RO, Carabello BA, Chatterjee K, de Leon AC Jr, Faxon DP, Freed MD, et al. 2008 Focused update incorporated into the ACC/AHA 2006 guidelines for the management of patients with valvular heart disease: a report of the American College of Cardiology/American Heart Association Task Force on Practice Guidelines (Writing Committee to Revise the 1998 Guidelines for the Management of Patients With Valvular Heart Disease): endorsed by the Society of Cardiovascular Anesthesiologists, Society for Cardiovascular Angiography and Interventions, and Society of Thoracic Surgeons. Circulation. 2008;118:e523-661.

27. Brown M, Holmes D, Tajik J, Sarano M, Schaff H. Safety of same-day coronary angiography in patients undergoing elective valvular heart surgery. Mayo Clin Proc. 2007;82:572-4.

28. Bahar I, Akgul A, Ozatik MA, Vural KM, Demirbag AE, Boran M, et al. Acute renal failure following open heart surgery: risk factors and prognosis. Perfusion. 2005;20:317-22.

29. Heringlake M, Knappe M, Vargas Hein O, Lufft H, Kindgen-Milles D, Bottiger BW, et al. Renal dysfunction according to the ADQI-RIFLE system and clinical practice patterns after cardiac surgery in Germany. Minerva Anestesiologica. 2006;72:645-54.

30. Provenchere S, Plantefeve G, Hufnagel G, Vicaut E, De Vaumas C, Lecharny JB, et al. Renal dysfunction after cardiac surgery with normothermic cardiopulmonary bypass: incidence, risk factors, and effect on clinical outcome. Anesth Analg. 2003;96:1258-64.

31. Rosner MH, Portilla D, Okusa MD. Cardiac surgery as a cause of acute kidney injury: pathogenesis and potential therapies. J Intensive Care Med. 2008;23:3-18.

\section{Discussion}

Dr John Byrne (Nashville, Tenn). I have questions about potential surrogates that you may have perhaps overlooked. What about these patients just being more complex patients, having bigger operations? I think the clamp times were longer. They were bigger, more complex operations. Did they have low cardiac output syndrome requiring all of those inotropes after surgery, which was the cause of renal failure, not necessarily the catheterization 24 hours prior?

Dr Hennessy. Yes, as everybody knows, ARF may be a surrogate for postoperative low cardiac output syndrome. This may be the case for some patients. We certainly tried to match for this as best as we could. Patients were equivalent on preoperative ejection fraction and their heart failure class, and so we attempted to match for that as best as we could between those 2 groups. ARF may be a surrogate for other major adverse events, meaning that it may just be one of the complications that occur because of some other reason. This may be true for some patients, and in other patients ARF may be the cause of some of their complications. This is probably especially true in patients who undergo dialysis, have higher rates of infection, and have longer intensive care unit stays.

With regard to that it might relate to the classic question of which comes first, the chicken or the egg, this is a bit difficult to tease out, and it is definitely not something that we specifically looked at in these groups of patients. We know that ARF is one cause of a significant amount of morbidity and mortality in these patients, and we believe that this is at least one simple and effective way that we may be able to help prevent ARF and perhaps at least lessen some of the complications after surgery.

Dr Byrne. I ask that, because in our hybrid catheterization laboratory operating room, we routinely catheterize patients, hundreds of patients, and we just haven't seen this. Now, it is true that if a patient sustains a major adverse event that compounds the injury, he/she is probably more likely to develop renal failure and all these other complications.

So as a follow-up now, how about a patient with tight aortic stenosis, someone who has really, really tight aortic stenosis and now requires aortic valve replacement. I know Mike Davidson at the Brigham is catheterizing them himself just before surgery. Are you recommending waiting 2448 hours in those patients?

Dr Hennessy. I think I would look at it in 2 different perspectives. In patients with tight aortic stenosis, if they have lived with their symptoms for weeks, months, and years, maybe 24 hours won't make much of a difference for them, but it definitely depends on the specific patient and how he/she presents. If it is clearly somebody who presents in an emergency case, we don't recommend delaying surgery. You clearly have to do what is best for the patient. Our center believes that maybe some of what happens is part of a 2hit process to the kidneys. The kidneys might take a first hit with the contrast load and then a second hit subsequently with undergoing surgery, and it might be the case that if you combine this together one time on the table that it diminishes the risk or the kidneys just take one hit and maybe you don't have as much renal failure afterward. That is definitely something to look at in the future and try to tease out.

Dr Robert Kramer (Portland, Me). Congratulations on an excellent presentation. Your conclusions are fully supported by work that our group presented at the STS meeting in January. 
We use the Acute Kidney Injury Network definition for acute kidney injury, which has a lower threshold than the STS definition. We found that when the cardiac surgery admission was separated from the cardiac catheterization admission, the incidence of acute kidney injury was reduced by $45 \%$. Short- and long-term survivals are compromised in patients with acute kidney injury. Your work may further the opportunity to change a standard of care. We now encourage our colleagues to separate the surgical admission from the catheterization admission whenever possible. Of course, there are times when urgent surgery is compelling and one can't delay, but there are times, as you mentioned, that you can.

Our analysis did not clearly answer the question as to how long to delay surgery after cardiac catheterization. What is your recommendation when asked that question?

Dr Hennessy. In this group of patients, and, of course, this is a retrospective study, so I think further studies should be done in the future to validate what we found, there should be at least 24 hours before patients proceed to surgery. Now, whether a greater amount of time might help the patients more and reduce their injury even greater, I think that is something that needs to be studied, but at this time I think at least 24 hours should be separated between the time of catheterization to the time of surgery.

Dr Harold Lazar (Boston, Mass). I have 2 questions to ask. I noticed that you chose to look at renal function by measuring creatinine, and if you look at the patients who did and did not have renal failure postoperatively, the difference was approximately 1.1 versus 1.3 and the $P$ value was .06 . But I wonder whether you looked at glomerular filtration rate, which is a more sensitive indicator of renal function. You might have seen a difference between those patients who developed renal failure postoperatively regarding their preoperative glomerular filtration rate.

Dr Hennessy. That is a good point. Clearly there are many different ways of setting acute kidney injury, and glomerular filtration rate is one of those ways, and that might be one of the limitations of our study. However, according to the other variables we looked at, we focused on STS definitions, and so we wanted to focus on an STS definition of renal failure.

Now, clearly the difference was 1.1 to 1.2 , I believe, and it was close to statistical significance. In a younger patient, that might not mean as much and maybe in an older patient it does, and I think that is something to study in the future and attempt to have a better definition of renal failure.

Dr Lazar. I think you may want to go back and look at those glomerular filtration rates, because they probably will be different.

My second question relates to the type of catheterization that was done. At our institution when we catheterize somebody before valve surgery, it is to see whether they have any coronary lesions, and we are only shooting the coronaries with a limited amount of dye, not doing a ventriculogram or attempting to cross the valves. So what type of catheterization was done, how much dye was used, do you actually know the amount of dye, and could you correlate those patients who developed renal failure with the amount of dye that they received preoperatively?

Dr Hennessy. With regard to the type of catheterization that was done, we took all patients and did not specifically do a subanalysis of what type they underwent. Originally one of our main questions was also the amount of contrast and the type of dye that were used and whether or not that also affects ARF after surgery. Unfortunately, that was difficult because a retrospective study is needed to find those answers within the patient's records, and that is something we are looking in the future to work on as a prospective study to see if that makes a difference.

Dr Ali Khoynezhad (Omaha, Neb). I'd like to follow up on one of the questions that was just brought up by a previous discussant, namely, the importance of using estimated glomerular filtration as a more sensitive measurement for renal function before and after any procedure. There are also the RIFLE criteria based on the Acute Dialysis Quality Initiative Group. This is the foundation that internationally recognized the consensus definition for ARF, endorsed by nephrologists. So that is something I suggest you may want to consider for future studies, so we can compare apples to apples.

I wonder if you can tell us also any protocols involving perioperative hydration of patients undergoing heart catheterization. Typical patients with heart disease are usually diuresed rather than given any fluid, which may be helpful for the right ventricle and the heart but counterproductive for the kidneys.

Dr Hennessy. For our patients, it clearly depended on the type of patient and the degree of heart failure. As you said, many of these patients are diuresed before surgery. So I think it was patient specific in terms of how much hydration these patients received before surgery.

Dr Lawrence Cohn (Boston, Mass). I have one last question that I want to ask in a socioeconomic vein. There is a huge national push by hospital administrators to have patients come in the same day, have the operation, and save a lot of preoperative days. Are the hospital administrators at the University of Virginia comfortable with the decision now that you are changing your protocol, or are you changing your protocol for admission catheterization surgery?

Dr Hennessy. Since the results of this study, we have changed our protocol and our administration is in full support. One of the things about the University of Virginia is that our patients come from a wide distance because the hospital covers such a wide area. So many of our patients come from 3 to 5 hours away, and for them, not only for the administration but for the patient, it would be a convenience for them to have their cardiac catheterization within the same hospitalization of their surgery. But we believe our administration has been supportive of us in delaying this time period, and in the future we will look to see that this will reduce the amount of renal failure after surgery in these patients. 